2

\title{
Perspectiva contemporânea das ideias de Paulo Freire
}

\section{Perspectiva contemporánea de las ideas de Paulo Freire Contemporary perspective of Paulo Freire's ideas}

Claudia Suely Ferreira Gomes

Universidade Federal da Paraíba [Brasil] csfg0312@gmail.com

ORCID ID: https:/ / orcid.org/0000-0003-4130-4935

Maria das Gracas Goncalves Vieira Guerra ${ }^{2}$ Universidade Federal da Paraíba [Brasil] gracinhavieira@yahoo.com.br ORCID ID: http:/ / orcid.org/0000-0002-6943-0338

Emilia Maria da Trindade Prestes ${ }^{3}$ Universidade Federal da Paraíba [Brasil] prestesemilia@yahoo.com.br ORCID ID: http:/ / orcid.org/0000-0001-8992-1399

Adriana Valeria Santos Diniz 4 Universidade Federal da Paraíba [Brasil] adrianavaleriasd@gmail.com

1 Mestre em Políticas Públicas, Gestão e Avaliação da Educação Superior - MPPGAV/CE/UFPB. Auditora.

2 Professora Associada III.

3 Professora Titular e Vicecoordenadora da Cátedra UNESCO de EJA.

4 Professora Associada da Universidade Federal da Paraíba. [Brasil). Coordenadora do Mestrado Profissional em Gestão de Organização Aprendentes [MPGOA] UFPB. 


\section{Resumo}

O pensamento pedagógico de Paulo Freire, revelando ser a educação dialógica uma questão essencial para uma maior leitura crítica da realidade, continua inspirando pedagogos/as, filósofos/as e sociólogos/as da educação de diferentes contextos, como forma de responder aos questionamentos e desafios das realidades emergentes, nas dimensões educativa, política e social da práxis pedagógica. A atualização do seu pensamento inspira este artigo guiado pelo seguinte questionamento: Como, em um mundo multicultural, se revelam, de forma atualizada as ideias de Freire, tendo como arcabouço pedagógico e político o diálogo? A partir de fontes documental-bibliográficas, utilizando uma abordagem descritiva, o estudo realizou uma reflexão teórica sobre a reinterpretação do pensamento educativo de um dos pensadores mais citados em diferentes fontes de referência, no mundo na área das ciências humanas, no país e no exterior. No Brasil, as teorias baseadas no diálogo e na participação, oriundas de Paulo Freire, se por um lado se tornaram objeto de crítica e de perseguição; por outro, diante de uma situação de crise e de desalento, vem sendo adotadas e defendidas, com maior vigor, como uma vertente da inclusão e de democracia. Por fim, o artigo defende que a perspectiva pedagógica de Paulo Freire continua vigente, na busca de um mundo plural em que se demanda reconhecimento e autonomia.

Palavras-chave: Educação, Retualização de freire, Diálogo.

\section{Resumen}

El pensamiento pedagógico de Paulo Freire, que revela que la educación dialógica es una cuestión esencial para una mayor lectura crítica de la realidad, sigue inspirando a pedagogos, filósofos y sociólogos de la educación de diferentes contextos, como una forma de responder a las preguntas y desafíos de las realidades emergentes, en las dimensiones educativas, políticas y sociales de la praxis pedagógica. La actualización de su pensamiento inspira este artículo guiado por la siguiente pregunta: ¿Cómo, en un mundo multicultural, se revelan las ideas de Freire de manera actualizada, teniendo como marco pedagógico y político el diálogo? A partir de fuentes documentales-bibliográficas y con un enfoque descriptivo, el estudio realizó una reflexión teórica sobre la reinterpretación del pensamiento educativo de uno de los pensadores más citados en diferentes fuentes de referencia, en el mundo de las ciencias humanas, en el país y en el extranjero. En Brasil, las teorías basadas en el diálogo y la participación, originales de Paulo Freire, se han convertido, por un lado, en objeto de crítica y persecución; por otro lado, ante una situación de crisis y desánimo, se han adoptado y defendido con mayor vigor como una vertiente de inclusión y democracia. Finalmente, el artículo defiende que la perspectiva pedagógica de Paulo Freire sigue vigente, en la búsqueda de un mundo plural en el que se exija reconocimiento y autonomía.

Palabras clave: Educación, Vigencia de Paulo Freire, Diálogo. 


\section{Abstract}

Paulo Freire's pedagogical thought, which reveals that dialogical education is an essential issue for a greater critical reading of reality, continues to inspire pedagogues, philosophers and sociologists of education from different contexts, as a way of responding to the questions and challenges of emerging realities, in the educational, political and social dimensions of pedagogical praxis. The updating of his thinking inspires this article guided by the following question: How, in a multicultural world, are Freire's ideas revealed in an updated way, having dialogue as a pedagogical and political framework? Based on documentary-bibliographic sources and with a descriptive approach, the study made a theoretical reflection on the reinterpretation of the educational thought of one of the most cited thinkers in different reference sources, in the world of human sciences, in the country and abroad. In Brazil, the theories based on dialogue and participation, original to Paulo Freire, have become, on the one hand, the object of criticism and persecution; on the other hand, in the face of a situation of crisis and discouragement, they have been adopted and defended with greater vigor as an aspect of inclusion and democracy. Finally, the article argues that Paulo Freire's pedagogical perspective is still valid, in the search for a plural world in which recognition and autonomy are demanded.

Key words: Education, Paulo Freire's work, Dialogue.

\section{Introdução}

Em 2015, durante uma manifestação política e amplamente divulgada pela mídia, foi visibilizada nacional e internacionalmente, a foto de uma faixa carregada por um grupo de manifestantes que dizia: "Chega de doutrinação marxista. Basta de Paulo Freire". Aquela faixa, que pedia "dar um basta em Paulo Freire", não só sugeria condenar ao silêncio o patrono da educação brasileira ${ }^{5}$ como tornava visíveis posições autoritárias de certos setores da sociedade, baseadas em intransigência e discriminação. As ideias desses grupos, de silenciar a linguagem e a palavra como forma de recriar e de transformar o mundo, representava uma forma de silenciar milhares de indivíduos, inclusive daqueles que ainda não nasceram, a medida em que fossem educados dentro de posições ideológicas consideradas portadoras do bem absoluto. Como comenta Llavador [2013, p. 111, tradução livre], "as maneiras de dizer o mundo, as relações entre linguagem e mundo tem reflexos mais direto nos modos de pensar a realidade e nas formas de comprometer-se com o mundo". Comprometimento esse, em prol da justiça social ou do respeito humano, para a construção da esperança - como defendia Freire em um dos seus últimos livros (Freire, 1992].

5 Paulo Freire foi declarado patrono da educação brasileira em 2012. 
Considerado um dos maiores educadores do século XX, Paulo Freire alicerçou a sua proposta educativa, enfatizando a amorosidade e a busca pela conscientização crítica dos alunos. Defendia o diálogo horizontal entre educador e educando, rompendo totalmente com as premissas do sistema educacional vigente à época, centrado na autoridade do professor. Escreveu Flecha [2003, p. 11], que a atual sociedade da informação necessita do compromisso proposto por Freire, dada a sua complexidade e conotação cultural múltipla. Essa sociedade requer diálogos nos seus processos de globalização, risco e reflexividade. Dai as contribuições da obra de Freire, para um contexto que requisita de ideias capazes de explicar e encontrar alternativas, frente aos desafios de uma totalidade fragmentada por seus processos dinâmicos.

No espaço escolar as suas contribuições se revelam nos diferentes exercícios que exigem renovações e interações entre aprendizagem e currículo, formação docente e gestão, ou seja, todos essas questões vigentes e problemáticas num tempo caracterizado por crescente complexidades e inseguranças e que necessita de sentido e de afirmação de igualdade entre os diferentes. Sendo a igualdade um princípio importante e transversal para a relação pedagógica, ela atravessa diversos campos da vida (Infante y Luca, 2020). Por isso, é possível reconhecer que as ideias de Freire continuam vigentes e atualizadas.

Freire, anunciava João Francisco de Souza [2002], um dos seus intérpretes, foi um pensador do seu tempo, com capacidade para manter-se atualizado e em constante movimento; em constante estado de aprendizagem, inclusive busca de superação dele próprio. Por isso, a atualidade de Paulo Freira compreende-se, segundo Souza, [2002] na capacidade do autor em situar-se mais além de um momento passado ou presente. Baseia-se nas "responsabilidades das práticas pedagógicas" e nas posturas éticas do ser com o outro/ser social.

Na contemporaneidade, os caminhos seguidos pelas várias pedagogias em suas conexões com cenários políticos, sociais e econômicos, demandam saberes e práticas educativas centradas em construções de processos emancipatórios; processos que possibilitem os sujeitos se construírem como seres humanos, históricos e autônomos. A busca pela emancipação e autonomia, um ideal da educação, presentes no pensamento de Freire, dão abertura a se defender a atualização das suas ideias nos tempos presentes.

A perspectiva contemporânea das ideias de Paulo Freire, portanto, direciona o desenvolvimento desse artigo. Nele tentaremos acompanhar a ideia colocada por João Francisco ${ }^{6}$ sob forma de hipótese, de que o pensamento pedagógico de Freire pode assumir o "caráter de uma nova utopia para o século XXI" ao se aproximar, de forma dialógica e transversal, do debate sobre o papel da educação na construção da inter/multiculturalidade crítica no interior da diversidade cultural, minimizando situações de desigualdades e discriminação.

\section{Situando as ideias de Paulo Freire no tempo contemporâneo}

Em tempos incertos, propostas pedagógicas que permitam aos sujeitos adquirirem condições de lutarem pela emancipação e autonomia pode ser um caminho para a construção e reconstrução de espaços de convivência e de transformações entre os diferentes [Haddad, 2019]. Trata-se de iniciativas político-pedagógicas envolvendo propostas efetivas de inclusão social e propiciando aos sujeitos vivenciarem o sonho de ter um amanhã melhor.

$6 \quad$ O livro objeto de referência é: Atualidade de Paulo Freire, de João Francisco de Souza. 
A construção de novos discursos centrados no respeito a diversidade cultural presentes em uma pedagogia dialógica, pode ser capaz de conduzir aprendizagens em todos os espaços da sociedade, de forma mais participativa e eficiente. Para Cortesão [2018, p. 176] é a partir de uma,

[...] prática empenhada e refletida que, ao longo da sua vida, foi emergindo todo o fascinante edifício teórico e de intervenção que Paulo Freire não cessou de questionar. Freire não cessou de se questionar e de questionar o contexto que o envolvia, como não cessou de utilizar tudo o que descobriu, no extraordinário contributo que deu para que possa existir um mundo menos injusto.

Estas preocupações, se constituem em um dos indicadores para situá-lo como um pensador contemporâneo, inserido no debate educacional e na prática pedagógica no interior da diversidade cultural, características da pós-modernidade e do mundo em renovação. A necessidade de se estabelecer, nos espaços educativos, formas mais agradáveis de convivência na pluralidade, como pregava Freire, significa a nova utopia pedagógica para o século XXI e, quiçá, para todo o terceiro milênio [Souza, 2002, p.14]. Quiçá, as inúmeras e diversificadas experiências vividas por Freire o ajudaram a ir ampliando a sua humanidade, contribuindo para ir construindo novas formas de pensar e de atuar no mundo. Com efeito, o educador que sistematizou as ideias da pedagogia do oprimido como forma de organização e prática socioeducativa dos sujeitos em situação de desvantagem educacional, social e econômica, foi o mesmo, adaptando as suas ideias, que lecionou em diferentes universidades estrangeiras e que assessorou os programas educacionais de governos chilenos, nicaraguenses, de São Tomé e Príncipe e de Guiné-Bissau, ampliando suas experiências e conhecimentos. Freire, regressando ao Brasil em 1980, depois de 15 anos de exílio, deu sequencia as suas atividades de educador, produzindo livros, ensaios, artigos, conferências e entrevistas [Beisiegel, 2010, p.15], período que, em conjunto com outros autores, escreve vários livros tendo o diálogo como o registro marcante.?

No final dos anos 90, Freire, dotando-se de novas experiências agora como Secretário de Educação do Estado de São Paulo - um Estado complexo e desafiante em termos dos inúmeros problemas socioeconômicos e políticos e das diferentes construções culturais que ali se interagem e se diferem - ampliou os seus escritos e suas reflexões sobre os problemas emergentes dessa sociedade multicultural e pós-moderna. $O$ lidar com o fazer educativo institucionalizado, em uma nova etapa do processo civilizatório - etapa de transformações, propiciou-lhe posicionar-se sobre questões relacionadas à política, à reforma educativa, financiamento e currículo, pedagogia, formação docente e gestão, ou seja, questões complexas e atemporais.

Ninguém ignora que a sociedade vive em constante tensão ou dialética entre o tradicional e o contemporâneo. No primeiro caso, a própria sociedade reflete formas conservadoras de gestar a sociedade e a educação. No segundo caso, simultaneamente, surgem fenômenos e ações revelando oposições e adequações ao novo momento, ainda que de forma ambivalente e contraditória.

Ante esse panorama e diante da necessidade de se repensar outra forma de concretar o social, surgem formas alternativas de ler a realidade e de apresentar críticas e posicionamentos no espaço coletivo. Este, talvez, tenha sido o caso do enredo de uma escola de samba do carnaval

7 Dentre essas produção destacam-se Pedagogia: diálogo e Conflito e Medo e Ousadia. 
brasileiro ${ }^{8}$, cuja temática, baseada na impotência do conhecimento e aprendizagem, lembrou Paulo Freire em uma das suas frases mais reconhecida: "não se pode falar de educação sem amor" [Gasda, 2019]. Aliás, como mencionava Freire [1992] no seu livro Pedagogia da Esperança, não se pode falar de educação sem sonhos e sem utopias. Não se pode barrar a possibilidade dos sonhos de um amanhã melhor. Não se pode proibir de se ter esperança. É acreditando nas possibilidades dos sujeitos terem, através de uma ação educativa dialógica, vivências capazes de Ihes possibilitarem transformações e mudanças em busca da construção de sua humanidade, que se desvela o conhecimento e a aprendizagem através do diálogo.

\section{Pedagogia dialógica de Paulo Freire: o diálogo como pressuposto de uma ação libertadora}

O conceito de diálogo, como lembra Brayner [2009, p. 21], não é unívoco. A construção de consenso sobre o seu significado "etimológico e semântico", mostra-se problemático e "no horizonte educativo" pode ser interpretado como uma "possibilidade de um encontro intersubjetivo carregado de potencial emancipatório". [Brayner, 2009, p.2].

Independentemente da sua tradição ou tradução, ou das dificuldades de se conquistar a igualdade através da utilização das novas formas de comunicação, "previsão e controle" da própria palavra [Brayner, 2009, p 21], a aceitação das teorias dialógicas como referencial ético, educativo e político e como uma práxis de transformação, emancipação e libertação, continuam presentes no discurso acadêmico e político no atual momento de um mundo que se aproxima - e se distancia - pelos novos processos econômicos, sociais, políticos, ideológicos, educacionais, tecnológicos e informacionais. No atual estágio da sociedade, reconhecido como o de segunda modernidade - ou pós-moderno, para outros -, valores e ideais surgidos com a modernidade como a universalização da educação, a democracia, liberdade, igualdade, direitos humanos revistos e reinterpretados, continuam sendo desafios e alternativas para a construção do futuro e da própria emancipação.

Na revisão dessas conquistas e dos valores que lhes dão os suportes universais, pensadores como Habermas [1981] com a teoria da ação comunicativa/linguística, Giddens [1987] com a teoria da estruturação/institucionais, Touraine [2003] com a unidade das diversidades, Beck [2011] com a teoria do risco, Luhmann [2016] com a teoria dos sistemas sociais/acoplamentos, Bourdieu [1991] com a distinção ou sentido prático/Habitus, Dubet [1994] com a experiência social, Castells [1997] com a Sociedade da informação e, sobretudo, a pedagogia do diálogo como transformação com [Freire, 1983], apesar de serem pensadas de forma biunívocas, revelam as interpretações clássicas dos fenômenos sociais, introduzindo novos elementos de análises nas suas interpretações sociológicas e educacionais com vistas a possibilitar explicações sobre as mudanças sociais em processo e o papel do sujeito/indivíduo na ordem emergente. Se por um lado, análises pessimistas sobre o destino da sociedade e da história são amplamente difundidas, por outro, outros teóricos procuram encontrar explicações para processos emergentes, inovadores e alternativas para melhorar as conquistas da modernidade.

No ângulo da linguagem, cultura e educação, autores como Chomsky [1965] com a competência e atuação, Searle [2001] e Austin [1965] com atos de falar, [Bernstein 1996] com os códigos sócio-semáticos, Giroux [2004] com a identidade e cultura, também, através de paradigmas

8 Escola de samba paulista Águia de Ouro. Carnaval 2020. Disponível em: https:/ / www.redebrasilatual.com. br/cultura/2020/02/com-homenagens-a-paulo-freire-aguia-de-ouro-e-campea-do-carnaval-de-sao-paulo/. Acesso em: 10 mar. 2020. 
comunicativos e dialógicos, buscam construir explicações e alternativas para oportunizar formas mais igualitárias para a participação da população.

No que tange aos estudos transculturais, encontramos nas obras de Vigotski [1989] com a teoria sociocultural/teoria da atividade, Popkewitz [1991] com a teoria da mudança educacional, Luria [2010] com as transformações históricas e processos de conhecimentos, Cole [1996] com a abordagem cultural-histórica, Matusov [2007] com o modelo de participação e Wells [1999] com a teoria da atividade do conhecer, preocupações pela participação e transformação de diferentes segmentos da sociedade através das práticas de aprendizagens aliadas aos processos sócio históricos.

No Brasil, as teorias baseadas no diálogo e na participação, oriundas de Paulo Freire, se por um lado se tornaram objeto de crítica e de perseguição, por outro, passam a ser revalorizadas e utilizadas como uma vertente da inclusão e de democracia. Os diferentes processos participativos, gerando espaços de discussão e de consenso, estendem a compreensão e a prática de espaços democráticos e a incorporação de novos elementos e mecanismos diversificados que facilitam a participação, a tomada de decisão e a transformação através de novos critérios e lógicas, tanto decorrentes da "diversidade das lógicas de ação" ou, segundo a preferência ou desejo, provenientes das "exigências de individualização", compreendido como as experiências sociais advindas de diferenciações e da libertação das normatizações sociais e institucionais (Wautier, 2003, p. 203-204).

0 reconhecimento internacional de Paulo Freire como um dos maiores e mais respeitados pedagogos contemporâneos, desde as mais populares universidades da África até as mais elitizadas como Harvard, Cambridge e Oxford, o tornam o terceiro teórico acadêmico mais citado no mundo. De acordo com Paiva [2016],

O criador da Pedagogia de Oprimido agora é citado em um novo e impressionante título de reconhecimento: Paulo Freire é o terceiro pensador mais citado do mundo em universidades da área de humanas. O levantamento foi feito através do Google Scholar - ferramenta de pesquisa para literatura acadêmica - por Elliot Green, professor associado da London School of Economics. Segundo ela, Freire é citado 72.359 vezes, atrás somente do filósofo americano Thomas Kuhn [81.311] e do sociólogo, também americano, Everett Rogers [72.780]. [Grifo das autoras]

Apesar desse reconhecimento internacional, Freire vem sofrendo, no Brasil, inúmeras críticas, tendo, inclusive, sido apresentado, em 2019, um projeto de lei ${ }^{9}$ propondo sua destituição da posição de patrono da educação brasileira, por representar "a eliminação do pensamento plural nas escolas e nos meios acadêmicos" [Correio Brasiliense, 2019).

Talvez as críticas ao seu pensamento se centrem no pressuposto, por ele defendido, da educação se tornar um benefício para todos de forma libertadora. Sobretudo uma educação capaz de contemplar a diversidade, as minorias étnicas, a pluralidade de doutrinas e os direitos humanos, ampliando o horizonte de conhecimentos e de visões do mundo. Seu pensamento pedagógico que enfoca o conhecimento numa visão prospectiva trabalha mais com significado do que com o conteúdo; mais com a subjetividade e a pluralidade do que com a igualdade e a unidade; mais

9 Projeto de Lei no 1930/2019 - Apresentado pelo deputado Heitor Freire [PSL/CE]. 
com a noção de poder local e de pequenos grupos. Valorizando o imediato, o afetivo, a relação, a intensidade, o envolvimento, a solidariedade e a autogestão, enfatiza a questão do saber em uma perspectiva emancipadora da educação e do sujeito.

Se a natureza política da educação continua vigente nas práticas educativas ao longo da vida, o diálogo freireano, como pressuposto de uma pedagogia libertadora, supõe uma convergência com as diferentes vozes que compõem a cidadania diversa e plural. Uma convergência capaz de renovar o sentido da cidadania nos nossos dias e inspirar novas formas de relatos.

\section{O Diálogo como requisito da educação cidadã}

Ninguém desconhece que as formas e os conteúdos da dominação mudaram, e hoje as concepções de emancipação, liberdade e de cidadania em um mundo cambiante é cada vez mais complexa. Nesta fase contemporânea, a busca de reconhecimento, desenvolvimento e transformação de diferentes setores explorados, oprimidos, subordinados, marginalizados, excluídos e invisibilizados se manifestam através de novos relatos. Esses novos relatos, manifestados em formas de narrativas, são atualmente observados na perspectiva de classe, de etnia, de gênero, como forma de dar sentido à vida social e individual. São lutas e relatos que aspiram uma cidadania plena, autônoma, autêntica e capaz de estabelecer uma convivência pacífica entre os diferentes.

Essas aspirações colocam na educação e nos processos educativos voltados para a emancipação e autonomia novas responsabilidades, tendo como centro a construção da humanidade do ser humano [Souza, 2001, pp. 63-64; Aquino y Almeida, 2006], arquitetada em torno do conhecimento e as possibilidade da convivência harmoniosa entre grupos diferentes.

As possibilidades da convivência juntos, apesar das diferenças, em um clima capaz de superar adversidades, violência, preconceitos e as diferentes formas de marginalização, presentes nas ideias de Freire, são condições essenciais referentes ao respeito e a dignidade de cada um. Um "imperativo ético".

Para ele, "o respeito à autonomia e à dignidade de cada um é um imperativo ético e não um favor que podemos ou não conceder uns aos outros" [Freire, 1996, p. 59]. Nessas contingencias Freire propõe o diálogo como elemento determinante para o desenvolvimento de grupos subalternos em busca da emancipação e da autonomia.

Talvez seja essa convivência pacífica e respeitosa entre os diferentes que marque a reatualização do olhar dialógico e educativo de Freire. Como comentou Souza [2002], a aceitação do outro diferente em um mundo que se torna cada vez mais multicultural e diverso se torna o grande desafio contemporâneo.

Com efeito, a nova grande utopia social e educativa para o século XXI e quiçá para o milênio reside nos ensinamentos para a convivência plural e harmoniosa, mesmo quando os velhos problemas continuem atualizados com os mesmos ou com outros tipos de vestuários.

Pensar em construir uma educação para o Século XXI na perspectiva freireana é, essencialmente, assumir como finalidade desenvolver um ser autônomo e reconhecido, mas que se realize na relação com os outros, na construção de uma nova sociedade. Assim, a finalidade dessa educação se fundamenta na concepção de homem histórico, autônomo e livre, vivendo solidariamente entre iguais num espaço e tempo determinados, no sentido de que ninguém pode ser livre se, em 
sua volta, há outros que não são. Freire ao reconhecer a educação dialógica como instrumento de construção da emancipação também reconheceu que o respeito às diferenças é condição indispensável para a estruturação das relações sociais e alternativas de práticas inclusivas.

Nessa abordagem, destacamos como questões fundamentais o chamamento e a acolhida do povo; a dialogicidade; a inserção crítica na realidade; a integração da escola no movimento interdisciplinar de currículo; a exigência da formação contínua dos professores e a articulação com os movimentos sociais. Em síntese, a preocupação com a articulação entre vida-realidade concreta e as várias dimensões do conhecimento sistematizado.

Portanto, a atualidade de Paulo Freire compreende-se, segundo Souza [2002], na capacidade dos processos educativos situarem-se mais além de um momento passado ou presente. É esse posicionamento que situa Freire como um pensador contemporâneo, inserido no interior do debate da diversidade cultural, que caracteriza a nossa pós-modernidade e o mundo em renovação.

\section{A reconfiguração da educação e seus desafios}

O panorama sócio educacional brasileiro, nas últimas décadas, vem possibilitando diferentes direcionamentos nas ações educacionais sejam elas formais, informais ou não formais.

Como se sabe, a realidade brasileira é, por excelência, um laboratório para a observação e desenvolvimento das teorias dialógicas e pelas lutas por superações sociais. No caso específico da região Nordeste, sua posição como "lócus" para a experimentação de inovadoras propostas educativas contemplando o diálogo, a participação e a transformação, é inegável. Trabalhos educacionais formais e extensionistas de diferentes organizações, onde se incluem as atividades desenvolvidas pelas Universidades, abrangem iniciativas da alfabetização de adultos, mulheres e operários - a exemplo do que foi o projeto Zé Peão na UFPB, nos trabalhos com os indígenas da região e nos assessoramentos aos diferentes movimentos sociais, onde se incluem as propostas de economia solidária, com projetos de incubadora de emprego. Somam-se ademais, a formação de professores das zonas rurais e urbanas e as organizações voltadas para o respeito aos grupos e as pessoas que fogem dos padrões de uma sociedade tradicional e excludente. Todas essas iniciativas marcaram e marcam a história educativa dessa região, que serviu de berço para a adoção dos princípios freireanos da busca da cidadania, através do diálogo.

Na visão de Paulo Freire, o Ser social é o centro do processo educacional e das práticas educativas emancipadoras. Para tanto, os grupos marginalizados devem "incorporar estratégias e critérios para a formação de pensamentos e subjetividades críticas e emancipadora" [Carrillo, 2013, p.27], suportadas por conhecimentos capazes de lhes permitir reconhecer as determinações sociais e históricas excludentes e as circunstâncias de supera-las. Quando esses grupos participam da construção do conhecimento, a partir da discussão da razão de ser dos saberes, os conteúdos ganham um significado prático [Brandão, 2017], apontando formas de superação.

Na contemporaneidade, as práticas educativas, sem considerar o contexto social e a presença do outro como sujeito autônomo e portador do direito de ser reconhecido, tendem a perder parte do seu significado libertador ou de perseguição da autonomia. Talvez fosse pensando no atual caminhar da história que as propostas de liberdade propostas por Freire, via uma educação libertadora, migraram para as de autonomia, como forma de responder as recentes formas de "dominação social" [Brayner, 2018, p.272]. 
Nesse novo contexto, o conhecimento adquirido necessita encontrar conexão com a vida real, para ser capaz de responder aos anseios de reconhecimento e de emancipação do Outro. E assim, gradativamente, tanto as propostas de liberdade como a de autonomia abrem passagem para os conceitos de autonomia e de reconhecimento, vistos como necessários para se combater as formas de opressão causadas pelo novo modelo econômico globalizado.

No modelo de sociedade vigente, onde imperam as formas de comunicação e informação baseadas nas tecnologias, a manutenção do silêncio dos grupos submetidos e de pouca escolaridade amplia as desigualdades e a aceitação passiva dos processos decisórios. Mais do que nunca persistem dinâmicas reprodutoras de exclusão, reflexo de uma sociedade que continua a ser organizada na desigualdade e nas hierarquias.

Tomando-se mais uma vez o exemplo da inquietante realidade sócio cultural da região nordestina brasileira, alvo das preocupações e dos ideais educacionais de Freire no passado, apesar da modernidade globalizada e dos avanços em termos de escolarização, movimentos sociais e ações das políticas públicas, as enormes diferenças sociais e econômicas continuam marcadas. Os dados estatísticos [Agência ibge, 2017] revelam a manutenção de cerca de dois terços de sua população jovem e adulta sem saber ler e nem escrever ou alfabetizados de forma precária, significando que as lic̣ões em vida e o acervo pedagógico legado por Freire não foram, ainda, capazes de derrubarem um muro erguido secularmente, de vozes silenciadas dos grupos de adultos analfabetos ou pouco letrados.

Nesta sociedade fechada, onde as relações de poder entre indivíduos e grupos continuam marcadas pelas diferenças econômicas, sociais e educacionais e pelas diferenças étnicas, de gêneros e de idade, as práticas educativas resistem em se desvincular de modelos pedagógicos teleológicos, normativos e conservadores, frutos das vivências culturais e da nossa formação histórica.

Como se vem comentando, em uma sociedade tradicionalmente marcada pelas desigualdades, torná-la um espaço onde as pessoas diferentes se respeitam e respeitam a identidade do outro se tornou uma exigência e uma necessidade. Entretanto, a grande dificuldade encontrada é saber que estratégias e categorias teóricas e práticas serão necessárias para o seu enfrentamento, no mundo atual

Talvez, na prática, não saibamos como propiciar uma educação capaz de minimizar os preconceitos, as discriminações e os conflitos identitários existentes na sociedade e no interior do estabelecimento escolar. Quiçá, necessitemos aprender a lidar com diferentes identidades na perspectiva da construção com o Outro, mudando as formas de convivências em um mundo cujas formas de "opressão" se diversificaram.

Mas, por outro lado, uma das lições dos processos históricos é que nenhum sistema ou instituição possui regras políticas e morais suficientemente resistentes e imutáveis e que toda cultura ou forma de convivência não é estática.

Logo, se por um lado, educadores, gestores e cidadãos continuam a repetir ensinamentos ou a utilizar estratégias pedagógicas praticamente sem utilidade para a modernidade tardia. Se no contexto contemporâneo se necessita de maior e melhor esclarecimentos conceituais sobre os termos "emancipação", "liberdade" "opressões", "direitos humanos ou justiça social", reconhecimento e autonomia, evitando redundâncias, como aponta alguns críticos de Freire; por 
outro lado, entendemos que na realidade social fugidia dos espaços educacionais da sociedade a vida se recria, e as aprendizagens não reveladas nos melhores resultados ou nos melhores índices da avaliação são capazes de se manifestarem em formas pedagógicas e em formas de convivências inovadoras.

Essas "escolas vivas" e muitas vezes invisíveis ao nosso olhar desatento e não crítico são aquelas capazes de assumir compromissos com as rupturas de uma situação desigual, injusta e discriminadora, fortalecendo os laços de solidariedade e as alternativas contra o fatalismo da reprodução, da reprovação ou da exclusão dos setores populares ou dos preconceitos existente no espaço escolar. Se por um lado, a dinâmica da produção estimula a manutenção ou surgimento de processos educativos que tendem a afirmar novas formas de discriminação e exclusão; por outro, faz muito tempo que as lutas por igualdade de oportunidade se fazem presente no mundo.

Seguindo Llavador [2013, p. 117, tradução livre] é possível entender que a atualidade de Freire se traduz em perceber a educação "como um princípio gerador; uma forma de vida social; um caminho que vamos construindo e reconstruindo a medida em vamos recorrendo". Por isso, o debate sobre as novas responsabilidades da educação, como preconizou Souza [2002], deve se sustentar na construção da humanidade do ser humano, em todos os aspectos e espaços. Situar Paulo Freire a partir dos valores mais significativos que movem as tradicionais e as atuais lutas dos sujeitos na busca pelo seu reconhecimento, direitos humanos e humanidade, o torna um pensador contemporâneo e um dos mais importantes e originais, em um mundo em profundo processo de transformação.

\section{Considerações finais}

A despeito das inúmeras críticas sofridas por Paulo Freire, suas ideias, como comentamos, reverberam até os dias atuais, demonstrando que essas ideias quando aplicadas em diferentes espaços educativos são capazes de inspirar formas de relacionamentos e atuação, construindo caminhos de reconhecimento do Outro. A noção de Diálogo ou de "Dialogia" proposta por Freire encerra a presença e o reconhecimento de quem não é o "Mesmo", culminando em adoção de ações coletivas para a promoção do bem comum. Isso implica em mudanças na relação estabelecida entre sociedade, indivíduos e educação, preparando pessoas para participarem de decisões que envolvem o bem-estar da coletividade e fortalecendo os ideais republicanos e democráticos.

Entretanto, na atual conjuntura brasileira, onde faixa pedindo dar um "basta em Paulo Freire" ou políticos propondo a "cassação do patronato" sinalizam o impedimento do debate público plural ou o confronto de pontos de vistas diferenciados, se acedem suspeitas sobre os rumos republicanos e democráticos da nação.

Nestes momentos de riscos e indefinições o pensamento de Freire, marcado por um ideário humanista e pela horizontalidade da relação pedagógica e por propostas de liberdade, autonomia e de indignação se reatualiza, possibilitando o surgimentos de processos educativos capazes de propiciar a elaboração do exercício do conhecimento, posicionamento e crítica das bases sociais que sustentam o atual discurso sobre a realidade," permitindo fazer uma avaliação do sentido ético destes fins" [Brayner, 2018, p. 277 ].

Paulo Freire em suas rodas de conversa costumava comentar sobre as vicissitudes da realidade social, as transformações do processo civilizatório e a necessidade de ser reinterpretado. 
Também reconhecia que "educação só pode ser exercida na liberdade; na opressão se faz doutrinação ou catequese" ( Brayner, 2017, p. 277). A emergência nesse novo momento demandando a anulação da figura ou das palavras de Freire, permite reconhecer a existência de barreiras ao exercício da liberdade, sinalizando, com a privação das opiniões plurais "instauração de um ambiente totalitário".

Independentemente dos posicionamentos políticos aportados pela atual conjuntura brasileira, conclui-se que a atualidade de Freire reside "na sua capacidade para situar-se mais além de um momento passado ou presente" [Souza, 2001, p.14]. Consideramos as suas preocupações, baseadas nas responsabilidades das práticas pedagógicas e nas posturas éticas os principais fatores que o situa como um pensador atemporal e, ao mesmo tempo, inserido nos recentes debates envolvendo a construção de sociedades plurais mais igualitárias e capazes de exprimir na totalidade a tolerância, o reconhecimento a emancipação.

\section{Referências}

Agência lbge. [2017]. PNAD Contínua 2016: 51\% da população com 25 anos ou mais do Brasil possuíam no máximo o ensino fundamental completo. Recuperado em 22 junho de 2020, de https://agenciadenoticias.ibge.gov.br/agencia-sala-deimprensa/2013-agencia-de-noticias/releases/18992-pnad-continua-2016-51-dapopulacao-com-25-anos-ou-mais-do-brasil-possuiam-no-maximo-o-ensino-fundamentalcompleto.

Aquino, M. A. y Almeida, F. [2006]. O olhar multicultural de Paulo Freire como uma prática de cidadania na educação: busca e recuperação. Recuperado em de: agosto de 2020, de http://www.bocc.ubi.pt/_esp/autor.php?codautor=618

Austin, J. L. [1995]. How to do Things with words. New York: Oxford University

Beisiegel, C. R. [2010]. Paulo Freire. Recife: Fundação Joaquim Nabuco, Editora Massangana, Coleção Educadores.

Beck, U. [2011]. Sociedade de risco: Rumo a uma outra modernidade. São Paulo: Editora 34.

Beltrán Llavador, J. [2013]. Ser para aprender. Los beneficios sociales de la educación a lo largo de la vida. In: Mollá, C. C. XIII Encuentro Estatal de Programas Universitarios para Mayores. Nuevos tiempos, Nuevos retos para los Programas Universitarios para Mayores. Valencia: Universitat de Valéncia, pp. 10-123.

Recuperado em 25 julho de 2020, de https://www.aepumayores.org/sites/default/files/ LIBRO CONGRESO XII VALENCIA.pdf

Bernstein, B. [1996]. Pedagogy, symbolic control and identity: theory, research, critique. Londres: Taylor and Francis.

Bourdieu, P. [1991]. Language and symbolic power. Cambridge: Polity Press. 
Brandão, C. R. [2017]. A educação como cultura. Memórias dos anos sessenta. Horizontes Antropológicos, Porto Alegre, v. 23, n. 49, pp. 377-407, set. Recuperado em 22 julho de 2020, de http://www.scielo.br/scielo.php?script=sci_arttext\&pid=\$010471832017000300377\&lng=pt\&nrm=iso.

Brayner, F. H. [2018]. Humanismo, anti-humanismo e Educação Popular. Pedagogia do Oprimido:50 Anos. Revista Interinstitucional Artes de Educar. Rio de Janeiro, 4 [2], 257-278, mai -ago. Dossiê 50 anos da Pedagogia do Oprimido: movimentos de opressões e emancipações contemporâneas na América Latina e África.

Recuperado em 10 agosto de 2020, de https://www.epublicacoes.uerj.br/index.php/ riae/article/view/38027/26698

Brayner, F. H. [2020]. A cassação de Paulo Freire. https:www.ihu.unisinos.br/186noticias/noticias-2017/572675-a-cassacao-de-paulo-freire. 16/10/2017. Recuperado em $05 / 10 / 2020$

Castells. M. [1997]. La era de la información. Economía, sociedad y cultura. Vol. 1. Madrid: Alianza Editorial.

Chomsky, N. [1965]. Aspects of the theory of syntax. Mouton.

Cole, M. [1996]. Cultural psychology: a once and future discipline. Cambridge: Belknap Press.

Cortesão, L. [2018]. O valor da prática em Paulo Freire. Reflexão e Ação. Santa Cruz do Sul, v. 26, n. 1, pp. 165-178, jan./abr. Recuperado em 22 junho de 2020, de https://online. unisc.br/seer/index.php/reflex/article/view/12014/pdf.

Correio Brasiliense [2019]. Deputado do PSL propõe tirar Paulo Freire como patrono da educação. Jornal eletrônico Correio Brasiliense, Brasília: 30 de maio. Recuperado em 22 junho de 2020, de https://www.correiobraziliense.com.br/app/noticia/eu-estudante/ensino educacaobasica/2019/05/30/ensino educacaobasica intern,758831/deputado-dopsl-propoe-tirar-paulo-freire-como-patrono-da-educacao.shtml.

Dubet, F. [1994]. Sociologia da Experiência. Lisboa: Instituto Piaget.

Flecha, R. [2003]. Compartiendo palabras. El Aprendizaje de las personas adultas a través del dialógo. Barcelona: Paidós Ibéria.

Freire, P. (1983). Pedagogia do oprimido. 12.ed. Rio de Janeiro: Paz e Terra.

Freire, P. [1992]. Pedagogia da Esperança: reencontro com a Pedagogia do Oprimido. Rio de Janeiro: Paz e Terra.

Freire, P, [1996]. Pedagogia da autonomia: saberes necessários à prática educativa. São Paulo: Paz e Terra. 
Gasda, E. [2019]. Paulo Freire: não se pode falar de educação sem amor. Dom total. 28 de fevereiro. Recuperado em 22 junho de 2020, de https://domtotal.com/ noticia/1336535/2019/02/paulo-freire-nao-se-pode-falar-de-educacao-sem-amor/.

Giddens, A. (1987). Um mundo desbocado. Los efectos de la globalización: Madrid; Taurus.

Giroux, H. A. [2004]. Cultural studies, public pedagogy and the responsibility of intellectuals. Communication and Critical/Cultural Studies, London, 1 [1], 59-79. Recuperado em 11 agosto de 2020, de https://www.tandfonline.com/doi/abs/10.1080/14791420 42000180926.

Habermas, J. [1981]. Teoría de la acción comunicativa. Racionalidad de la acción y racionalización social [Vol. I]. Madrid: Taurus.

Haddad, S. [2019]. Política, educação e atualidade do pensamento freiriano. Educação em Revista, 35, 27 de maio, pp. 1-16. Recuperado em 11 agosto de 2020, de https://www. scielo.br/pdf/edur/v35/1982-6621-edur-35-e214048.pdf

Infante-Malachias, M. E., \& de Luca, A. (2020). Atualidade/necessidade do pensamento de Paulo Freire: a experiência da prática docente em um cursinho popular. Revista Estudos Culturais, 1[5]. Recuperado de http://www.revistas.usp.br/revistaec/article/ view/170630

Luhmann, N. [2016]. Sistemas sociais: esboço de uma teoria geral. São Paulo, Vozes.

Luria, A. R. (2010). Desenvolvimento Cognitivo. 6.ed. São Paulo: Ícone.

Matusov, E. [2007]. In search of "the apropriate" unit of analisys for sociocultural research. Culture \& Psychology. Los Angeles/Londres/Nova/Singapura, Delhi Sage Publications, 13 [3], 307-333. Recuperado em 22 junho de 2020, de http://ematusov.soe.udel. edu/vita/Articles/Matusov,\%201n\%20search\%20of\%20\%60the\%20appropriate\%20 Unit\%20of\%20analysis\%20for\%20sociocultural\%20research,\%20C\&P,\%202007.pdf.

Paiva, V. [2016]. Paulo Freire é terceiro teórico mais citado em trabalhos acadêmicos no mundo. Hypeness. Recuperado em 22 junho de 2020, de https://www.hypeness.com. $\mathrm{br} / 2016 / 06 /$ paulo-freire-e-terceiro-teorico-mais-citado-em-trabalhos-academicos-nomundo/.

Popkewitz, T.S. [1991]. A political sociology of educational reform: power/knowledge in teaching, teacher education and research. New York: Teachers College Press.

Searle, J. [2001]. Actos de Habla. Madrid: Cátedra.

Souza, J. F. [2002]. A atualidade de Paulo Freire: contribuição ao debate sobre a educação na diversidade cultural, Recife: Bagaço. 
Touraine, A. [2003]. Poderemos Viver Juntos? Iguais e Diferentes. 2.ed. Petrópolis, RJ, Vozes.

Vygotsky, L. S. [1989]. Problemas de método. In: A formação social da mente. Tradução José Cipolla Neto, Luís Silveira Menna Barreto, Solange, Castro Afeche. 3. ed. São Paulo Martins Fontes.

Wautier, A. M. [2003]. Para uma Sociologia da Experiência. Uma leitura contemporânea: François Dubet. Sociologias, Porto Alegre,5 [9], pp. 174-214, jan./jun. Recuperado em 22 junho de 2020, de http://www.scielo.br/pdf/soc/n9/n9aO7

Wells, G. [1999]. Dialogic inquiry: Towards a sociocultural practice and theory of education. Cambridge: Cambridge University Press. 